\title{
ASPECTOS HISTÓRICOS E METODOLÓGICOS DA EVOLUÇÃO RECENTE DO PERFIL DISTRIBUTIVO BRASILEIRO
}

Fernando Augusto Mansor de Mattos

\footnotetext{
Resumo: O objetivo deste artigo é avaliar a evolução da distribuição pessoal e da distribuição funcional de renda desde o início da industrialização brasileira. Aspectos históricos e metodológicos serão levados em consideração para analisar os resultados empíricos.

Palavras-chave: Distribuição pessoal da renda. Distribuição funcional da renda. Desigualdade de renda.

Abstract: The objective of this article is to evaluate the personal income distribution and also the functional distribution of income since the beginning of the Brazilian industrialization. Historical and methodological aspects are taken into consideration so as to evaluate the empirical data.

Key words: Household income distribution. Factor income distribution. Income inequality.
}

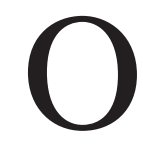

s estudiosos da questão da distribuição de renda defrontam-se com uma decisão intrigante quando pretendem avaliar o perfil distributivo de uma economia capitalista: de que forma será feita a abordagem da questão? Analisando-se dados de distribuição funcional da renda - aquela que separa a composição da renda global de um país entre os rendimentos do trabalho e os provenientes do capital? Ou estudando a distribuição pessoal da renda do trabalho - aquela que considera somente as rendas auferidas pelas pessoas no mercado de trabalho?

O primeiro objetivo deste texto é resgatar argumentos que mostrem a relevância dos dados que dizem respeito especificamente à renda do trabalho para a análise do perfil distributivo de uma economia capitalista, em especial uma economia de industrialização tardia, como a brasileira (CARDOSO DE MELLO, 1982). O estudo da questão a par- tir de uma avaliação da distribuição funcional da renda esbarra em dificuldades metodológicas e representa uma forma de análise que pode se mostrar insuficiente, por si só, para avaliar as múltiplas dimensões das desigualdades presentes em economias de capitalismo tardio, como a brasileira.

Para ilustrar a complexidade do fenômeno da desigualdade no caso brasileiro, o artigo mostra como o processo de estruturação do mercado de trabalho brasileiro moldouse a partir de uma crescente perspectiva de ampliação das desigualdades de renda; tanto no que se refere à distribuição pessoal, como à distribuição funcional de renda.

Para tanto, o artigo está dividido em três tópicos. O primeiro tem um caráter teórico/metodológico, e discute as relações entre a distribuição funcional da renda e a distribuição pessoal da renda do trabalho. O segundo discute 
conceitualmente o tema da heterogeneidade estrutural ${ }^{1}$ que caracterizou, historicamente, a industrialização brasileira. O terceiro apresenta resultados empíricos que ilustram aspectos discutidos nos tópicos anteriores. Por fim, as considerações finais buscam relacionar as principais questões reunidas ao longo do trabalho.

\section{DISTRIBUIÇÃO FUNCIONAL VERSUS DISTRIBUIÇÃO PESSOAL DA RENDA}

A captação dos dados relativos aos rendimentos do capital apresenta alguns problemas metodológicos. Alguns autores têm desenvolvido técnicas para a avaliação da distribuição funcional de renda na economia brasileira, ${ }^{2}$ mas defrontam-se, muitas vezes, com as próprias dificuldades de captação de dados referentes à divisão entre a renda apropriada pelo capital e a pelo trabalho. Na maioria dos casos, o estudo da divisão funcional da renda é realizado dentro de alguns setores específicos, notadamente na indústria. Os dados de renda do setor industrial apresentam maior precisão por referirem-se a atividades que mantêm relações de trabalho predominantemente formais e a terem indicadores mais organizados. De qualquer forma, trata-se apenas de estimativas, muitas vezes obtidas através de avaliações da massa de rendimentos do trabalho (que é a forma mais precisa de captação de dados de renda) e posterior cálculo dos rendimentos do capital por subtração do total de rendimentos do trabalho em relação ao montante calculado para o valor adicionado na produção industrial. Essa forma de estimar a divisão funcional da renda encontra, entretanto, algumas imprecisões, especialmente quando são computados os ordenados dos gerentes e diretores de alguns segmentos industriais, pois é difícil distingui-los, muitas vezes, entre os rendimentos que remuneram a força de trabalho ou o capital investido.

Vale destacar que, o mercado de trabalho brasileiro apresenta-se acentuadamente segmentado. Portanto, avaliar apenas as modificações na distribuição funcional da renda seria - mesmo desconsiderando os problemas metodológicos inerentes a esta opção - pouco conclusivo para medir a verdadeira dimensão da desigualdade presente nesta economia, pois os rendimentos do trabalho se comportam de maneira bastante diferenciada (BACHA, 1975), existindo grande dispersão salarial tanto dentro dos setores industriais (dispersão intra-setoriais), como também entre setores industriais de diferentes níveis de produtividade (dispersão inter-setoriais). É por isso que a maior parte dos estudos sobre a evolução da distribuição da renda no
Brasil toma como referência os dados relativos à renda do trabalho (levando em conta, nesse universo, os salários dos empregados com ou sem carteira de trabalho assinada, os rendimentos dos trabalhadores por conta-própria e os rendimentos a título de "pró-labore" dos empregadores) - pois os mesmos são mais precisos do que as informações relativas à distribuição funcional da renda. Os dados sobre a evolução da distribuição funcional da renda muitas vezes servem para qualificar e incrementar estudos sobre a evolução dos rendimentos pessoais e, quando acompanhados dos dados de distribuição pessoal da renda do trabalho, as informações sobre a distribuição funcional servem para descrever de forma mais acurada o quadro distributivo brasileiro. $^{3}$

A participação dos rendimentos do trabalho na renda total gerada na economia brasileira vem decaindo nas últimas décadas, atingindo proporções inferiores inclusive às de países de nível de renda per capita e grau de desenvolvimento econômico semelhantes. ${ }^{4}$ Esse quadro pode ser considerado mais trágico quando se constata, a partir dos estudos mais recentes a respeito do tema, que tem sido observada uma tendência de deterioração do perfil dos rendimentos, mesmo dentro da parcela da renda nacional que se destina a remunerar o trabalho.

Metodologicamente, os dados da distribuição pessoal da renda do trabalho são obtidos por meio de pesquisas domiciliares, feitas por amostragens estratificadas, nas quais as pessoas são entrevistadas e declaram seus rendimentos aos pesquisadores. Apesar de algumas dificuldades dessa forma de captação de dados (pois muitos trabalhadores recebem rendimentos com freqüência irregular ao longo do mês; outros não sabem precisamente quanto ganham - algo que se mostrava particularmente mais difícil de precisar durante o período dos elevados níveis inflacionários; e existem também casos de subdeclaração de rendimentos, entre outros problemas ${ }^{5}$ ), esse método permite não só computar os rendimentos provenientes de relações formais de trabalho (para as quais existem fontes de dados bastante precisas - por exemplo, os relatórios da Rais, ou publicações de entidades empresariais, como a Fiesp, ou, ainda, as guias de contribuição sindical), como também dos trabalhos informais ou eventuais, que têm peso importante no espaço ocupacional da economia brasileira.

Portanto, cabe novamente a questão: qual a relevância da análise de dados relativos aos rendimentos do trabalho para o estudo da questão distributiva na economia brasileira? 
$\mathrm{Na}$ verdade, para uma avaliação mais completa da evolução do perfil distributivo brasileiro das últimas décadas, seria interessante combinar resultados tanto das alterações da distribuição funcional da renda como da distribuição pessoal da renda do trabalho. Entretanto, devido às dificuldades metodológicas para avaliar sua distribuição funcional, a opção pela análise dos dados relativos à distribuição pessoal da renda constitui uma forma adequada de abordar a questão distributiva brasileira e de avaliar sua evolução. O argumento presente neste artigo é que a distribuição da renda pessoal proveniente do trabalho está intimamente relacionada à distribuição funcional da renda na economia brasileira. A extrema concentração funcional da renda condiciona e delimita o perfil da distribuição da renda do trabalho na sociedade brasileira. A distribuição da riqueza capitalista define os fluxos de renda do capital (em suas diversas modalidades: juros, lucros, dividendos, aluguéis, etc.) e também molda as condições sociais e econômicas em que a força de trabalho é remunerada nos processos produtivos.

\section{HETEROGENEIDADE ESTRUTURAL DA ECONOMIA BRASILEIRA}

A principal característica do mercado de trabalho brasileiro é sua acentuada segmentação, o que se configura como um reflexo imediato da heterogeneidade setorial determinada historicamente pelo processo de desenvolvimento capitalista do país. Desta forma, o mercado de trabalho brasileiro pode ser dividido entre um mercado externo de trabalho e um segmento denominado "mercado interno de trabalho" (EDWARDS; REICH; GORDON, 1975).

No mercado interno de trabalho estão os empregados dos setores industriais organizados, geralmente com forte característica oligopolística. Dentro dele, os salários e postos de trabalho são determinados por uma certa estrutura ocupacional que obedece a regras administrativas próprias, relacionadas a fatores tecnológicos que não estão presentes nos setores mais atrasados da economia.

No mercado externo de trabalho, ao contrário, os trabalhadores não precisam apresentar quase nenhuma qualificação e suas remunerações são determinadas por fatores mais aleatórios do funcionamento do mercado de trabalho em geral, as chamadas "forças de oferta e de demanda", que variam com intensidade mais elevada de acordo com as flutuações do ciclo econômico. No mercado externo de trabalho estão presentes os trabalhadores sem qualificação, tanto dos setores mais atrasados da economia, como ainda aqueles localizados na base da pirâmide ocupacional dos setores oligopolizados da estrutura produtiva (faxineiros, vigias, etc. das empresas com alta concentração de capital).

Portanto, a dinâmica da determinação salarial difere bastante nos dois casos, especialmente em um tipo de desenvolvimento como o do brasileiro, marcado por significativa exclusão social. O processo de exclusão e a evolução tecnológica eliminaram preferencialmente os postos de trabalho de mais baixa remuneração, aqueles cujos trabalhadores são mais desqualificados. Isso ocorre especialmente nos setores industriais mais dinâmicos. Esse processo tende a deprimir ainda mais a possibilidade de recuperação dos rendimentos reais dos trabalhadores do mercado externo de trabalho, mesmo quando a conjuntura econômica torna-se mais favorável ao aumento geral do nível de produção e de emprego. O enorme "exército industrial de reserva" e a pronunciada informalização do mercado de trabalho brasileiro nos últimos anos - especialmente a partir do início da década de $80-{ }^{6}$ quando também se ampliaram os mecanismos de flexibilização do mercado de trabalho brasileiro, ${ }^{7}$ além dos ínfimos patamares em que sempre esteve o salário mínimo no Brasil, colaboraram para que se consolidasse uma expressiva diferença salarial entre os estratos do mercado de trabalho brasileiro. Conforme lembra Souza (1980), uma recuperação do valor real do salário mínimo teria tido um papel fundamental para a redução das desigualdades de renda do trabalho existentes em uma economia como a brasileira, na qual uma parcela expressiva dos rendimentos do trabalho gravita em torno e/ou é mesmo determinada institucionalmente pelo valor do salário mínimo. ${ }^{8}$

A ampla diferenciação dos rendimentos do trabalho existente na economia brasileira reflete uma estrutura setorial bastante heterogênea, determinada historicamente, a qual está relacionada à convivência de setores avançados tecnologicamente (que têm um grande poder de mercado 9 e, portanto, uma grande capacidade de gerar lucros, devido à sua situação oligopolística) ao lado de segmentos ainda bastante atrasados tanto em termos de qualidade dos produtos quanto em termos de processo de trabalho.

Esta característica de elevada produtividade de alguns setores de ponta da economia brasileira (inclusive, em muitos casos, comparando-se a padrões internacionais) está associada não só à posição oligopolística desfrutada por essas empresas comerciais/industriais, mas também à possibilidade desses setores mais dinâmicos pagarem re- 
duzidos salários a uma parcela de sua mão-de-obra (especificamente aquela recrutada no mercado externo de trabalho), permitindo que uma grande parcela do valor adicionado seja absorvida na forma de lucros. Isto acontece mesmo com a existência de uma complexa hierarquia representada pelo mercado interno de trabalho das empresas oligopolistas, cujos integrantes recebem altos salários, muitas vezes até equiparáveis às remunerações recebidas em funções semelhantes exercidas em empresas localizadas nos países centrais.

Em poucas palavras, a possibilidade de remunerar uma parcela significativa de sua mão-de-obra com salários relativamente reduzidos permite aos principais e mais dinâmicos setores capitalistas da economia brasileira o pagamento de elevada remuneração a alguns segmentos de sua estrutura ocupacional sem que sejam deprimidas as suas margens de lucro ${ }^{10}$ - favorecendo, portanto, a concentração funcional da renda.

Dessa maneira, são promovidas enormes diferenças salariais dentro de algumas empresas tanto do setor industrial, quanto do setor comercial, incluindo os bancos. Essas diferenças intra-setoriais somam-se às enormes diferenças intersetoriais existentes na economia brasileira. Vale reforçar que essas acentuadas diferenças nas remunerações do trabalho são viabilizadas pelo fato de que existe uma grande parcela de mão-de-obra excedente de baixa qualificação que pode ser mobilizada pelo capital nos seus momentos de expansão e desmobilizada sem maiores ônus nas fases descendentes do ciclo econômico. Esse contingente de mão-de-obra pouco qualificada faz com que, mesmo nos momentos de maior aquecimento econômico, não ocorram pressões por uma recuperação do valor real das remunerações de base da estrutura ocupacional (DEDECCA, 1990). Em suma, os fatores estruturais da economia brasileira, aliados à opção política de impedir, por exemplo, que o Estado brasileiro patrocinasse uma ampla recuperação do valor real do salário mínimo nacional nos anos de maior prosperidade (notadamente na época do "milagre brasileiro", quando se ampliou a dispersão salarial, em um momento de supressão das liberdades políticas e sindicais), fizeram com que se conformasse uma estrutura de rendimentos acentuadamente desigual, em um mercado de trabalho pouco estruturado em sua base e excessivamente flexível (OLIVEIRA; MATTOSO, 1996).

As diferenças existentes (em termos de lucratividade, capacidade tecnológica e de participação nos mercados de bens e serviços) entre os vários segmentos produtivos da economia brasileira estão coladas às diferenças das remunerações no mercado de trabalho brasileiro. Por isso, a elevada concentração pessoal da renda do trabalho, no Brasil, está intimamente relacionada a uma elevada concentração funcional da renda.

Dessa forma, o estudo da distribuição pessoal da renda do trabalho descreve uma forma bastante representativa da questão distributiva, em particular no caso da sociedade brasileira. Esses dados, analisados ao lado dos dados da evolução da distribuição funcional da renda, revelam um quadro bastante completo da realidade distributiva brasileira. É do estoque de capital e de sua composição que derivam os fatores que levam a um certo perfil distributivo dos rendimentos, ${ }^{11}$ tanto em termos funcionais, quanto da renda do trabalho.

\section{ESTRUTURAÇÃO E DESESTRUTURAÇÃO DO MERCADO DE TRABALHO BRASILEIRO E SEUS IMPACTOS SOBRE A DISTRIBUIÇÃO DA RENDA}

Um estudo mais acurado acerca da constituição da estrutura ocupacional do mercado de trabalho brasileiro nas últimas décadas permite apreender, de forma mais clara, como se constituíram as determinações dos salários nesse mercado de trabalho, e, a partir daí, a distribuição dos rendimentos do trabalho.

Os dados da Tabela 1 revelam que entre 1940 e 1980, enquanto a população total e a população economicamente ativa (PEA) cresciam a uma taxa média anual, respectivamente, de cerca de 2,7 e 2,6\%, o emprego formal assalariado com carteira assinada crescia a uma taxa média anual que superava $6 \%$ (o conjunto do assalariamento ou seja, o assalariamento que inclui as contratações com registro em carteira e as sem registro - cresceu também expressivamente acima das variações da PEA e da população total: cerca de 3,6\% ao ano em média). Essa expressiva diferença, acumulada durante um largo período de tempo (quarenta anos), fez aumentar de maneira destacada o peso do emprego assalariado formal (e também o do assalariamento em seu conjunto) nas ocupações do mercado de trabalho brasileiro no período. Como contrapartida, reduziu-se o peso relativo da ocupação por conta própria e reduziu-se também a taxa de desemprego, assim como a taxa de subutilização da mão-de-obra, definida por Pochmann (1999) como uma somatória das seguintes situações: trabalhadores por conta própria (ou autônomos); trabalhadores sem remuneração (situação mais encontrada nos setores agrícolas, cujo peso - diga-se de 
TABELA 1

Evolução da População Economicamente Ativa, segundo Condição de Ocupação e Desemprego

Brasil - 1940-1980

\begin{tabular}{|c|c|c|c|c|}
\hline Indicadores & 1940 & 1980 & $\begin{array}{l}\text { Variação Absoluta } \\
\text { Anual (Em milhares) }\end{array}$ & $\begin{array}{l}\text { Variação Relativa } \\
\text { Anual (Em \% a.a.) }\end{array}$ \\
\hline População Total & $41.165,3$ & $119.002,3$ & $1.945,9$ & 2,69 \\
\hline PEA (№s Absolutos) & $15.751,0$ & $43.235,7$ & 687,1 & 2,56 \\
\hline PEA $(\%)$ & 100,0 & 100,0 & & \\
\hline Empregador & 2,3 & 3,1 & 24,4 & 3,32 \\
\hline Conta-Própria & 29,8 & 22,1 & 121,5 & 1,79 \\
\hline Sem Remuneração & 19,6 & 9,2 & 22,3 & 0,63 \\
\hline Assalariado & 42,0 & 62,8 & 513,4 & 3,59 \\
\hline Com Registro & 12,1 & 49,2 & 484,2 & 6,22 \\
\hline Sem Registro & 29,9 & 13,6 & 29,3 & 0,56 \\
\hline Desempregado & 6,3 & 2,8 & 5,5 & 0,50 \\
\hline Taxa de Subutilização (1) & 55,7 & 34,1 & 149,3 & 1,13 \\
\hline
\end{tabular}

Fonte: IBGE. Censos Demográficos e Estatísticos do Brasil; MTb (apud Pochmann, 1999).

(1) Conta-própria, sem remuneração, desempregado.

passagem - também diminuiu expressivamente no período); e trabalhadores desempregados. Portanto, a marca da estruturação do mercado de trabalho brasileiro, ao longo do período entre 1940 e 1980, foi não apenas a forte expansão (em termos absolutos) do volume de ocupações, mas também o aumento significativo - e sem precedentes históricos - do peso relativo dos empregos com registro formal nos setores organizados do mercado de trabalho brasileiro. É possível concluir facilmente, pelos dados expostos, que cerca de $80 \%$ do total das ocupações criadas no período eram ocupações baseadas no assalariamento - das quais mais de $85 \%$ de assalariamento formalizado.

Desde logo, é preciso sublinhar o significado da inserção do trabalhador com registro formal nos setores chamados aqui de "setores organizados" do mercado de trabalho brasileiro. A ampliação do número de trabalhadores com registro formal (carteira de trabalho assinada) naqueles setores representa a ampliação do número de trabalhadores sujeitos ao estatuto legal que regulamenta as relações de trabalho, o que significa dizer que são trabalhadores que passam a estar amparados legalmente pela legislação do trabalho (CLT), com tudo o que isso significa em termos de direitos sociais, trabalhistas e de segurança (relativa) no emprego. Ou seja, são trabalhadores que passam a ter acesso aos direitos mínimos da cidadania, como a representação sindical, a proteção do trabalho, a possibilidade de questionar na Justiça do Trabalho, eventualmente, a empresa em que trabalha (ou em que tenha trabalhado), assim como têm direito à remuneração plena do trabalho, segundo a legislação. ${ }^{12}$ Trata-se, portanto, de uma situação em que o trabalhador fica muito menos sujeito, do que o trabalhador sem registro em carteira, às incertezas próprias do funcionamento do mercado de trabalho de uma economia capitalista, dotando sua inserção ocupacional de uma maior proteção e segurança social do que se estivesse trabalhando precariamente sem registro em carteira ou em atividades por conta-própria. ${ }^{13}$

Os dados da Tabela 2 reforçam as conclusões e explicam os dados retirados da tabela anterior ao descrever o processo de industrialização que marcou o período entre 1940 e 1980. Os dados revelam um crescimento médio anual de cerca de $5 \%$ nas ocupações do setor secundário, com destaque para as ocupações no setor organizado da indústria. Também o setor organizado do terciário revelou expressivo crescimento (próximo de $5 \%$ ao ano em média ao longo desse largo período de 40 anos). Como resultado das mudanças setoriais, o peso relativo da indústria e da construção civil no conjunto das ocupações cresceu expressivamente no período, revelando o dinamismo industrial do período. Apenas para chamar a atenção para esse dinamismo industrial do período, vale lembrar que, conforme mostram as informações da Tabela 1, a população economicamente ativa cresceu cerca de $2,6 \%$ em média, ao ano, no 
período, enquanto que as ocupações do setor secundário, conforme mostram os dados da Tabela 2, cresceram aproximadamente $5 \%$. Ou seja, o processo de industrialização nacional foi expressivo e culminou com um processo de vigorosa e consistente estruturação do mercado de trabalho brasileiro, ${ }^{14}$ situação que somente se reverteria após os anos 80, quando a economia brasileira foi marcada pela reversão das elevadas taxas de crescimento do produto interno bruto - PIB, pela queda dos salários reais e pela inflação crônica e elevada.

A Tabela 3 mostra a reversão da trajetória anterior de estruturação do mercado de trabalho brasileiro. Como mostra vasta literatura, ${ }^{15}$ a reversão econômica brasileira, iniciada com a recessão dos primeiros anos da década de 80 , com a crise da dívida externa, e perpetuada pelas diversas tentativas de "ajustes" macroeconômicos fracassados (que, a partir de então, tentaram romper o crônico processo inflacionário brasileiro), fizeram com que os anos 80 legassem uma herança de baixas taxas médias de crescimento do PIB e dos níveis agregados de emprego. A marca da crise no mercado de trabalho brasileiro foi a expansão do setor informal e a queda dos rendimentos médios reais dos trabalhadores. Consolidou-se, ademais, uma nova trajetória de ampliação da desigualdade dos rendimentos, dessa vez (ao contrário dos anos 60 e 70, quando tais informações passaram a ser medidas de forma mais consistente e que revelaram aumento geral dos rendimentos, mas de forma bastante diferenciada, ou seja, concomitante "aumento do bolo" e ampliação das desigualdades de renda) com queda dos rendimentos médios reais. ${ }^{16}$

A expansão da economia passou a depender, nos anos 80, do esforço exportador para honrar os encargos da dívida externa. $\mathrm{O}$ assalariamento deixou de expandir seu peso no conjunto da ocupação: ele crescia a taxas semelhantes à do próprio crescimento da PEA entre 1890 e 1991. Entretanto, a desaceleração da economia, as incertezas relacionadas à inflação e a expansão da "financeirização" da dívida interna promoveram um cenário macroeconômico precário e provocaram uma queda da taxa de investimentos produtivos, com efeitos nefastos sobre as formas de contratação da mão-de-obra. Dessa forma, a precarização do mercado de trabalho manifestou-se na expansão das contratações fora dos registros legais. Ou seja, ampliouse o peso do assalariamento sem carteira assinada. Esse fenômeno ocorreu dentro do setor industrial, conforme mostra a Tabela 4, e também no setor terciário. A expansão do peso do emprego sem carteira e das atividades nãoorganizadas no conjunto do mercado de trabalho brasileiro entre 1980 e 1991 ocorreu, portanto, tanto por causa da precarização geral das contratações dentro de cada setor de atividade, quanto também pela própria queda do peso das atividades industriais, que concentram maior peso de

TABELA 2

Evolução das Ocupações Não-Agrícolas, segundo Segmentos Organizados e Não-Organizados Brasil - 1940-1980

\begin{tabular}{|c|c|c|c|c|}
\hline Segmentos & 1940 & 1980 & $\begin{array}{c}\text { Variação Absoluta } \\
\text { Anual (Em milhares) }\end{array}$ & $\begin{array}{l}\text { Variação Relativa } \\
\text { Anual (Em \% a.a.) }\end{array}$ \\
\hline Total Não-Agrícola (em milhares) & $4.914,3$ & $29.526,3$ & 615,3 & 4,58 \\
\hline Total Não-Agrícola (em \%) & 100,0 & 100,0 & & \\
\hline Organizado & 61,6 & 70,5 & 444,7 & 4,94 \\
\hline Não-Organizado & 38,4 & 29,5 & 170,6 & 3,90 \\
\hline Secundário & 30,2 & 36,2 & 230,1 & 5,05 \\
\hline \multicolumn{5}{|l|}{ Indústria de Transformação } \\
\hline Organizado & 17,8 & 20,2 & 127,2 & 4,92 \\
\hline Não-Organizado & 6,4 & 5,0 & 29,1 & 3,94 \\
\hline Construção Civil & 6,0 & 11,0 & 73,8 & 6,18 \\
\hline Terciário & 69,8 & 63,8 & 385,2 & 4,35 \\
\hline Organizado & 40,8 & 44,8 & 280,6 & 4,83 \\
\hline Não-Organizado & 29,0 & 19,0 & 104,6 & 3,40 \\
\hline
\end{tabular}

Fonte: IBGE. Censos Demográficos e Estatísticos do Brasil; MTb (apud Pochmann, 1999). 
atividades organizadas (e de emprego assalariado com carteira assinada) em seu interior.

No agregado, conforme mostram os dados da Tabela 4, o peso dos setores não-organizados no conjunto das ocupações do mercado de trabalho brasileiro, entre os Censos de 1980 e de 1991 , cresceu de $29,5 \%$ para $34,5 \%$. Ou seja, em apenas onze anos, o peso dessas atividades, que tinham retrocedido cerca de 9 pontos percentuais (no conjunto da ocupação) entre 1940 e 1980, voltaram a crescer pouco mais da metade dessa magnitude (saltando cinco pontos percentuais entre 1980 e 1991). Tal comparação revela a rapidez com que os avanços promovidos pelo

TABELA 3

Evolução da PEA, segundo Condição de Ocupação e Desemprego Brasil - 1980-1991

\begin{tabular}{|c|c|c|c|c|}
\hline Indicadores & 1980 & 1991 & $\begin{array}{l}\text { Variação Absoluta } \\
\text { Anual (Em milhares) }\end{array}$ & $\begin{array}{l}\text { Variação Relativa } \\
\text { Anual (Em \% a.a.) }\end{array}$ \\
\hline População Total & $119.002,3$ & $146.825,7$ & $2.529,4$ & 1,93 \\
\hline PEA (№s Absolutos) & $43.235,7$ & $58.456,2$ & & \\
\hline PEA (\%) & 100,0 & 100,0 & $1.383,7$ & 2,78 \\
\hline Empregador & 3,1 & 3,9 & 85,4 & 4,95 \\
\hline Conta-Própria & 22,1 & 23,9 & 401,4 & 3,51 \\
\hline Sem Remuneração & 9,2 & 5,4 & $-74,5$ & $-1,72$ \\
\hline Assalariado & 62,8 & 62,6 & 858,3 & 2,75 \\
\hline Com Registro & 49,2 & 36,6 & 11,2 & 0,05 \\
\hline Sem Registro & 13,6 & 26,0 & 847,1 & 9,01 \\
\hline Desempregado & 2,8 & 4,2 & 113,1 & 6,64 \\
\hline Taxa de Subutilização (1) & 34,1 & 34,2 & 477,1 & 2,81 \\
\hline
\end{tabular}

Fonte: IBGE. Censos Demográficos e Estatísticos do Brasil; MTb (apud Pochmann, 1999).

(1) Conta-própria, sem remuneração, desempregado.

TABELA 4

Evolução das Ocupações Não-Agrícolas, segundo Segmentos Organizados e Não-Organizados Brasil - 1980-1991

\begin{tabular}{|c|c|c|c|c|}
\hline Segmentos & 1980 & 1991 & $\begin{array}{l}\text { Variação Absoluta } \\
\text { Anual (Em milhares) }\end{array}$ & $\begin{array}{l}\text { Variação Relativa } \\
\text { Anual (Em \% a.a.) }\end{array}$ \\
\hline Total Não-Agrícola (em milhares) & $29.526,3$ & $42.624,3$ & $1.190,7$ & 3,39 \\
\hline Total Não-Agrícola (em \%) & 100,0 & 100,0 & & \\
\hline Organizado & 70,5 & 65,5 & 645,7 & 2,70 \\
\hline Não-Organizado & 29,5 & 34,5 & 545,0 & 4,88 \\
\hline Secundário & 36,2 & 30,6 & 214,0 & 1,83 \\
\hline \multicolumn{5}{|l|}{ Indústria de Transformação } \\
\hline Organizado & 20,2 & 14,6 & 23,5 & 0,39 \\
\hline Não-Organizado & 5,0 & 6,9 & 133,2 & 6,47 \\
\hline Construção Civil & 11,0 & 9,1 & 57,3 & 1,63 \\
\hline Terciário & 63,8 & 69,4 & 976,7 & 4,19 \\
\hline Organizado & 44,8 & 46,3 & 591,6 & 3,70 \\
\hline Não-Organizado & 19,0 & 23,1 & 385,1 & 5,24 \\
\hline
\end{tabular}

Fonte: IBGE. Censos Demográficos e Estatísticos do Brasil; MTb (apud Pochmann, 1999). 
período da industrialização acelerada dos anos 40 aos 70 , em termos de estruturação do mercado de trabalho brasileiro, foram em parte revertidos pela crise deflagrada nos anos 80 .

A Tabela 5 mostra a evolução, durante a primeira parte da década de 90, dos mesmos indicadores das tabelas anteriores. Um primeiro dado que chama a atenção é que, entre 1989 e 1995, a taxa média anual de crescimento da PEA foi de apenas $2 \%$, contra cerca de $2,8 \%$ entre 1980 e 1991 . Ao mesmo tempo, a taxa de criação de postos de trabalho, no período mais recente analisado, foi pior ainda do que havia sido durante o período 1980-1991. O assalariamento, entre 1989 e 1995 , cresceu a uma taxa média anual de apenas cerca de $0,5 \%$, contra mais de $2,7 \%$ entre os censos de 1980 e 1991 . O registro em carteira, no período mais recente em análise, teve redução em termos absolutos. Como resultado desse forte movimento de reversão econômica que caracterizou a primeira metade da década de 90, a taxa de desemprego, que já estava subindo no final dos anos 80 , atingindo $4,2 \%$ em 1991, chegou a cerca de $6,5 \% \mathrm{em}$ 1995.

A recessão econômica do governo Collor, o fracasso dos Planos Collor I e II, a paralisia da economia no período que culminou com o impeachment do então presidente e o processo de abertura comercial descuidada e exagerada realizado pelos governos Collor, Itamar e FHC promoveram uma forte retração das atividades industriais, com efeitos significativos e inequívocos na estrutura setorial do emprego não-agrícola, conforme apontam os dados da Tabela 6: queda do peso da indústria de transformação no conjunto das ocupações contrabalançada por um crescimento "por inchaço" do setor terciário, pois no interior deste ocorreu uma forte expansão das atividades não-organizadas, com aumento do peso de $22 \%$ para $30 \%$ em apenas seis anos. Ao mesmo tempo, a participação das atividades organizadas no interior da indústria de transformação reduzia-se dramaticamente - a uma média de cerca de 1 ponto percentual por ano, entre 1989 e 1995.

Organizada de forma diferente das tabelas anteriores, mas igualmente eloqüente em seus dados, a Tabela 7 mostra que, no segundo mandato de FHC, a situação do mercado de trabalho brasileiro continuou a se deteriorar - o que é particularmente preocupante quando se lembra que no início do governo FHC já havia um quadro social de tal forma preocupante que o mundo do trabalho brasileiro vivia uma situação dramática. Os dados da Tabela 7 revelam uma contínua ampliação da taxa de desemprego entre 1993 e 2002, ao mesmo tempo em que a PEA crescia a taxas superiores às do crescimento da população -, e esse aumento da entrada de pessoas no mercado de trabalho expõe provavelmente, uma estratégia das famílias para tentar recompor a renda familiar. Essas mudanças na estrutura do mercado de trabalho brasileiro refletem-se nos perfis distributivos, tanto no que se refere à distribuição da renda do trabalho, quanto ao peso dos rendimentos do trabalho na renda nacional (ou seja, a distribuição funcional da renda).

TABELA 5

Evolução da PEA, segundo Condição de Ocupação e Desemprego Brasil - 1989-1995

\begin{tabular}{|c|c|c|c|c|}
\hline Indicadores & 1989 & 1995 & $\begin{array}{l}\text { Variação Absoluta } \\
\text { Anual (Em milhares) }\end{array}$ & $\begin{array}{l}\text { Variação Relativa } \\
\text { Anual (Em \% a.a.) }\end{array}$ \\
\hline População Total & $144.293,1$ & $153.374,6$ & 734,7 & 0,91 \\
\hline PEA (№s Absolutos) & $62.513,2$ & $70.750,5$ & & \\
\hline PEA (\%) & 100,0 & 100,0 & $1.372,9$ & 2,08 \\
\hline Empregador & 4,2 & 3,9 & 22,3 & 0,83 \\
\hline Conta-Própria & 21,2 & 22,4 & 432,6 & 3,02 \\
\hline Sem Remuneração & 7,6 & 9,0 & 269,4 & 5,00 \\
\hline Assalariado & 64,0 & 58,2 & 194,7 & 0,48 \\
\hline Com Registro & 38,3 & 30,9 & $-350,0$ & $-1,41$ \\
\hline Sem Registro & 25,7 & 27,3 & 541,5 & 3,12 \\
\hline Desempregado & 3,0 & 6,5 & 442,1 & 15,80 \\
\hline Taxa de Subutilização (1) & 31,8 & 37,8 & $1.144,10$ & 5,07 \\
\hline
\end{tabular}

Fonte: IBGE. Censos Demográficos e Estatísticos do Brasil; MTb (apud Pochmann, 1999). (1) Conta-própria, sem remuneração, desempregado. 
No auge do regime militar brasileiro, a divulgação dos dados do Censo Demográfico de 1970 deu origem a um debate, que fez história, acerca da natureza do aumento da desigualdade na economia brasileira. A comparação entre os dados dos censos de 1960 e os de 1970 revelava que a desigualdade na distribuição de renda no Brasil havia aumentado (e continuaria a aumentar ao longo dos anos 70, conforme mostram os dados da Tabela 8, e ao longo dos anos 80, conforme mostram os dados da Tabela 9). Não havia dúvidas quanto ao fato de que a desigualdade havia aumentado. O debate instalou-se em torno das razões dessa realidade. Essa discussão colocou em campos opostos os formuladores da política econômica do governo militar e seus adversários.

TABELA 6

Evolução das Ocupações Não-Agrícolas, segundo Segmentos Organizados e Não-Organizados Brasil - 1989-1995

\begin{tabular}{|c|c|c|c|c|}
\hline Segmentos & 1989 & 1995 & $\begin{array}{l}\text { Variação Absoluta } \\
\text { Anual (Em milhares) }\end{array}$ & $\begin{array}{l}\text { Variação Relativa } \\
\text { Anual (Em \% a.a.) }\end{array}$ \\
\hline Total Não-Agrícola (em milhares) & $46.587,10$ & $51.506,40$ & & \\
\hline Total Não-Agrícola (em \%) & 100,0 & 100,0 & 819,9 & 1,69 \\
\hline Organizado & 66,7 & 59,3 & $-88,4$ & $-0,28$ \\
\hline Não-Organizado & 33,3 & 40,7 & 908,3 & 5,15 \\
\hline Secundário & 30,9 & 26,3 & $-141,5$ & $-0,96$ \\
\hline \multicolumn{5}{|l|}{ Indústria de Transformação } \\
\hline Organizado & 15,9 & 11,7 & $-230,2$ & $-2,89$ \\
\hline Não-Organizado & 6,5 & 6,7 & 70,4 & 2,20 \\
\hline Construção Civil & 8,5 & 7,9 & 18,1 & 0,45 \\
\hline Terciário & 69,1 & 73,7 & 961,4 & 2,79 \\
\hline Organizado & 46,5 & 43,6 & 132,3 & 0,60 \\
\hline Não-Organizado & 22,6 & 30,1 & 829,1 & 6,66 \\
\hline
\end{tabular}

Fonte: IBGE. Censos Demográficos e Estatísticos do Brasil; MTb (apud Pochmann, 1999).

TABELA 7

Evolução do Emprego, PEA e Desemprego, Antes e Depois do Plano Real Brasil - 1993-02

\begin{tabular}{|c|c|c|c|c|}
\hline Ano & $\begin{array}{c}\text { Total de Ocupados } \\
\text { (Em milhões de pessoas) }\end{array}$ & $\begin{array}{c}\text { PEA } \\
\text { (Em milhões de pessoas) }\end{array}$ & $\begin{array}{c}\text { Nível de Ocupação } \\
\text { (\% de Pessoas Ocupadas de } \\
\text { dez anos ou mais de idade) }\end{array}$ & $\begin{array}{c}\text { Taxa de Desemprego (1) } \\
\text { (Em \% da PEA) }\end{array}$ \\
\hline 1993 & 62,39 & 66,94 & 57,3 & 5,1 \\
\hline 1995 & 65,38 & 70,05 & 57,6 & 4,6 \\
\hline 1996 & 64,29 & 69,58 & 55,1 & 5,4 \\
\hline 1997 & 65,57 & 71,63 & 55,4 & 5,7 \\
\hline 1998 & 66,13 & 73,28 & 54,8 & 7,6 \\
\hline 1999 & 69,18 & 77,24 & 55,1 & 7,6 \\
\hline 2001 & 71,65 & 79,66 & 54,8 & 6,2 \\
\hline 2002 & 74,11 & 82,22 & 55,7 & 7,1 \\
\hline
\end{tabular}

Fonte: IBGE; FGV.

(1) Segundo critério do IBGE. 
TABELA 8

Distribuição da Parcela da Renda Total Apropriada, segundo Estratos Populacionais Brasil - 1960-1980

\begin{tabular}{lccc} 
& & & Em porcentagem \\
\hline Estratos Populacionais & 1960 & 1970 & 1980 \\
\hline $1 \%$ Mais Rico & n.d. & 13,8 & 14,9 \\
$10 \%$ Mais Ricos & 38,9 & 46,4 & 47,7 \\
$50 \%$ Mais Pobres & 17,7 & 15,6 & 14,6 \\
$20 \%$ Mais Pobres & n.d. & 3,8 & 3,4 \\
\hline
\end{tabular}

Fonte: IBGE.

A publicação de um livro de Langoni (1973) representava os argumentos oficiais do regime militar defendidos por um de seus principais integrantes. Segundo a avaliação de cunho ortodoxo/conservador - a desigualdade seria decorrente das próprias virtudes da expansão econômica do período, que geraria maior demanda por mão-de-obra qualificada (de maior nível de escolaridade), em detrimento da demanda por mão-de-obra menos qualificada, fato que ampliava as desigualdades de rendimentos existentes no seio do mercado de trabalho brasileiro. Essa interpretação apregoava que, no longo prazo, à medida que o crescimento econômico se consolidasse, o mercado se encarregaria de promover uma redução das desigualdades, por promover também o aumento na demanda por mão-de-obra não-qualificada. A ampliação inicial das desigualdades, segundo a doutrina oficial, não deveria ser vista como algo nefasto, posto que o aumento da renda dos mais ricos promoveria a expansão dos investimentos, possibilitando maior longevidade ao ciclo econômico ascendente. Do outro lado do debate, diversos autores reunidos em obra de Tolipan e Tinelli (1975) contestavam os argumentos dos defenso- res do regime militar, mostrando, entre outros fatores, que, mesmo entre os trabalhadores de mais altas rendas, havia aumentado a diferença de rendimentos. Segundo Malan e Wells (1975), a maior parte das desigualdades ocorridas naquele período devia-se ao aumento de desigualdades dentro do mesmo grupo educacional da força de trabalho - o que jogava por terra o que o próprio Langoni apregoara como a principal causa do aumento das desigualdades de renda no período: a variável "educação". ${ }^{17}$ Houve também os que apregoavam a perda de oportunidade de promover um aumento expressivo no salário-mínimo no período de prosperidade, quando as condições econômicas para tal eram mais presentes. ${ }^{18}$

De qualquer forma, o que mais interessa, neste artigo, é mostrar que a distribuição pessoal da renda deteriorou-se no período da industrialização brasileira. Ou seja, apesar da significativa estruturação do mercado de trabalho brasileiro, ocorrida entre 1940 e 1980, a economia brasileira ainda ostentava características de uma economia subdesenvolvida, na qual a heterogeneidade estrutural manifestava-se de diversas formas, inclusive pela elevada concentração da renda do trabalho.

O processo de concentração da renda também pode ser interpretado pela ótica da distribuição funcional da renda. A Tabela 10 mostra que, desde as décadas iniciais da industrialização, a participação da renda do trabalho na renda nacional vem caindo sistematicamente. Os dados do IBGE revelam que, em 1949, o trabalho participava com cerca de $57 \%$ da renda nacional. Essa parcela foi minguando ao longo das décadas seguintes, atingindo modestos $40 \%$ no final do século XX.

Dados mais recentes e rigorosos (Tabela 11), citados em Dedecca (2003), revelam que, ao longo dos anos 90, a parcela da remuneração dos empregados ${ }^{19}$ na renda

TABELA 9

Distribuição Pessoal da Renda do Trabalho, segundo Grupos de Renda

Brasil - 1981-1995

\begin{tabular}{|c|c|c|c|c|c|c|}
\hline Grupos de Renda & 1981 & 1986 & 1990 & 1992 & 1993 & 1995 \\
\hline $1 \%$ Mais Rico (\%) & 12,1 & 14,0 & 13,9 & 13,1 & 15,5 & 13,4 \\
\hline $10 \%$ Mais Ricos (\%) & 44,9 & 47,3 & 48,1 & 45,1 & 49,0 & 47,1 \\
\hline $50 \%$ Mais Pobres (\%) & 14,5 & 13,5 & 12,0 & 14,0 & 12,9 & 13,3 \\
\hline $10 \%$ Mais Pobres (\%) & 0,9 & 1,0 & 0,8 & 0,8 & 0,7 & 1,0 \\
\hline Índice de Gini (1) & 0,564 & 0,584 & 0,602 & 0,575 & 0,603 & 0,592 \\
\hline
\end{tabular}

Fonte: IBGE. Pesquisa Nacional por Amostra de Domicilios - PNAD.

(1) Varia de zero (perfeita igualdade) a 1 (total desigualdade). 
TABELA 10

Evolução da Distribuição Funcional da Renda - Parcela da Renda do Trabalho na Renda Nacional

Brasil - 1949-1999

\begin{tabular}{lc}
\hline Ano & $\begin{array}{c}\text { Renda do Trabalho } \\
\text { (em \% do PIB) }\end{array}$ \\
\hline 1949 & 56,6 \\
1959 & 55,5 \\
1970 & 52,0 \\
1980 & 50,0 \\
1991 & 49,0 \\
1994 & 46,0 \\
1998 (1) & 42,0 \\
1999 (1) & 41,3 \\
\hline
\end{tabular}

Fonte: IBGE.

(1) Estimativa

nacional decresceu de cerca de 37,5\%, em 1991, para apenas cerca de $32,8 \%$ em 1999, queda expressiva para um período relativamente curto de tempo, quando são considerados indicadores de caráter estrutural como esse. Os salários, em particular, tiveram uma redução de quase seis pontos percentuais de sua parcela no período, caindo de $32 \%$ para cerca de $26,5 \%$. Enquanto isso, cresciam o excedente operacional bruto (grosso modo, pode-se considerar como o lucro das empresas) e os impostos cobrados à produção.

O Gráfico 1 ilustra esse fenômeno e revela que, já na partida do Plano Real, as curvas de salários e lucros invertiam-se e continuariam a distanciar-se ao longo da década de 90, enquanto ao mesmo tempo a participação dos impostos na renda nacional galgava patamares cada vez mais elevados.

\section{GRÁFICO 1}

Distribuição Funcional da Renda

Brasil - 1991-1999

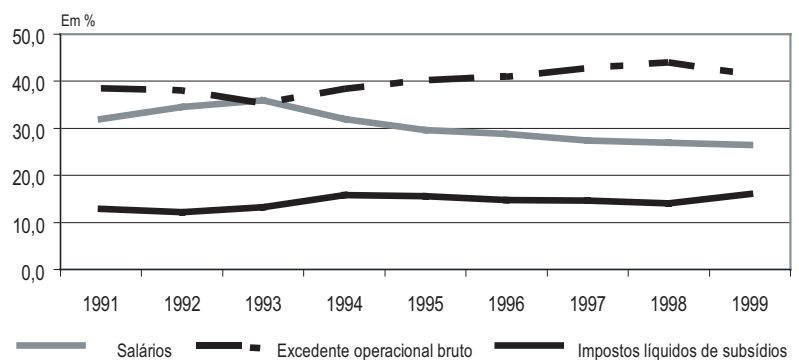

Fonte: IBGE.

Por fim - e sem a preocupação de ser exaustivo - podese apresentar mais um indicador da deterioração do perfil distributivo na economia brasileira como decorrência da implementação do Plano Real e - principalmente - pelo que o mesmo representou em termos da inserção da economia brasileira no cenário da economia globalizada. ${ }^{20}$

A política cambial e a elevação das taxas de juros reais na economia brasileira, no primeiro mandato de FHC, tiveram múltiplos efeitos: sobre a balança comercial, em particular, e sobre as transações correntes do balanço de pagamentos; sobre o nível e produção do emprego industrial; sobre a atividade econômica em geral (PIB); e também sobre as contas públicas. A elevação das dívidas externa e interna foi um resultado inequívoco do período. Um dos efeitos mais nefastos de tal cenário foi a ampliação do peso

TABELA 11

Componentes do Produto Interno Bruto pela Ótica da Renda Brasil - 1991-1999

\begin{tabular}{|c|c|c|c|c|c|c|c|c|c|}
\hline \multirow[b]{2}{*}{ Componentes } & \multirow[b]{2}{*}{1991} & \multirow[b]{2}{*}{1992} & \multirow[b]{2}{*}{1993} & \multirow[b]{2}{*}{1994} & \multirow[b]{2}{*}{1995} & \multirow[b]{2}{*}{1996} & \multirow[b]{2}{*}{1997} & \multicolumn{2}{|c|}{ Em porcentagem } \\
\hline & & & & & & & & 1998 & 1999 \\
\hline Produto Interno Bruto & 100,0 & 100,0 & 100,0 & 100,0 & 100,0 & 100,0 & 100,0 & 100,0 & 100,0 \\
\hline Remuneração dos Empregados & 37,5 & 40,2 & 41,7 & 36,6 & 34,3 & 34,6 & 33,0 & 32,4 & 32,8 \\
\hline $\begin{array}{l}\text { Salários } \\
\text { Contribuições Sociais Efetivas }\end{array}$ & $\begin{array}{r}32,0 \\
5,5\end{array}$ & $\begin{array}{r}34,6 \\
5,5\end{array}$ & $\begin{array}{r}35,9 \\
5,8\end{array}$ & $\begin{array}{r}32,0 \\
4,6\end{array}$ & $\begin{array}{r}29,6 \\
4,7\end{array}$ & $\begin{array}{r}28,8 \\
5,8\end{array}$ & $\begin{array}{r}27,4 \\
5,6\end{array}$ & $\begin{array}{r}26,9 \\
5,5\end{array}$ & $\begin{array}{r}26,5 \\
6,2\end{array}$ \\
\hline Contribuições Sociais Imputadas & 4,2 & 3,4 & 3,4 & 3,5 & 4 & 3,9 & 3,9 & 4,1 & 4,7 \\
\hline Rendimentos de Autônomos & 7,0 & 6,3 & 6,3 & 5,7 & 5,9 & 5,7 & 5,7 & 5,5 & 5,1 \\
\hline Excedente Operacional Bruto & 38,5 & 38,0 & 35,4 & 38,4 & 40,3 & 41 & 42,9 & 44,0 & 41,4 \\
\hline $\begin{array}{l}\text { Impostos Líquidos de Subsídios } \\
\text { sobre a Produção e Importação }\end{array}$ & 12,9 & 12,2 & 13,2 & 15,8 & 15,6 & 14,8 & 14,6 & 14,0 & 16,0 \\
\hline
\end{tabular}


das despesas financeiras no conjunto das despesas públicas.

A proporção dos gastos com pagamentos de juros da dívida interna em comparação com os gastos da esfera social ampliou-se aceleradamente e de forma sem precedentes ao longo dos anos 90. Em 1995, os gastos com juros e com encargos da dívida interna representavam cerca de $21,4 \%$ do total dos gastos sociais e, em 2001, 31,6\% (FILGUEIRAS, 2000). Essa é também uma forma de manifestação da acelerada deterioração do perfil distributivo brasileiro, ocorrida nos anos mais recentes, e que não é captada pelos indicadores mais tradicionais de distribuição da renda do trabalho (divisão da renda nacional por estratos de rendimentos do trabalho).

\section{CONSIDERAÇÕES FINAIS}

A dificuldade em analisar a evolução do perfil distributivo brasileiro reside no fato de que a industrialização brasileira moldou-se sob uma forte heterogeneidade estrutural, aprofundando assimetrias e criando outras dentro da estrutura produtiva e social brasileira.

A distribuição da renda do trabalho é uma maneira bastante representativa de descrever essa heterogeneidade, marcada por acentuado processo de concentração funcional da renda. Essa concentração aprofundou-se no período da industrialização pesada, o que explicitou a convivência de setores modernos e dinâmicos da atividade produtiva brasileira ao lado de setores atrasados tecnologicamente, em um mercado de trabalho que era completamente desestruturado. Em que pesem as transformações ocorridas no mercado de trabalho, o caráter tardio da industrialização brasileira não permitiu que os setores modernos que se instalaram na estrutura produtiva "arrastassem" todos os demais setores da economia. A sociedade e a economia foram profundamente transformadas (urbanização, montagem de um mercado de trabalho dinâmico, sofisticação do setor exportador, etc.), mas as desigualdades foram perenizadas - dado que não foi possível historicamente criar, no Brasil, as instituições que, nos países centrais, permitiram que a industrialização se fizesse acompanhar também por mudanças sociais e políticas.

A distribuição da renda do trabalho é um reflexo das características peculiares da estrutura produtiva que se conformou na economia brasileira desde que se instalou no país a indústria pesada e resulta, também, da forma como se distribuiu a riqueza capitalista nesse período, conforme lembrou Gonçalves (1999). O processo de industrialização que se intensificou no Brasil a partir dos anos 50 teve como resultado a conformação de uma marcante heterogeneidade estrutural - da estrutura produtiva - que carrega consigo uma heterogeneidade da estrutura ocupacional que lhe é correspondente, a qual, por sua vez, reflete-se em uma elevada desigualdade dos rendimentos do trabalho. Essa dispersão da renda do trabalho ocorre tanto em termos dos rendimentos provenientes de salários, quanto daqueles dos trabalhadores autônomos, que buscam formas alternativas de sobrevivência no mercado informal de bens e serviços. ${ }^{21}$

O trágico da realidade distributiva brasileira é que ela possui componentes políticos e históricos que consolidam essa situação de elevada exclusão social. Esses vários componentes (econômicos ou não) atuam continuamente, reforçando esse quadro de elevadas desigualdades, ${ }^{22}$ por meio das decisões de política econômica, da atuação da Justiça, de aspectos econômicos institucionais (tributação regressiva, por exemplo), da definição de regras de sociabilidade, entre outros, que não são quantificados pelos dados de distribuição pessoal da renda.

Os dados empíricos apresentados neste trabalho revelam que a sociedade brasileira tem sido marcada, desde o início da industrialização pesada, por um processo de deterioração do seu perfil distributivo, tanto do ponto de vista da distribuição pessoal da renda, quanto no que se refere à distribuição funcional. Em que pese o processo de expressiva estruturação do mercado de trabalho do país ao longo das décadas de auge do processo industrializante, a heterogeneidade estrutural persistiu na economia brasileira, manifestada pelas amplas diferenças de renda pessoal do trabalho ao longo desse período. O mais grave é que, quando eclode a crise dos anos 80 , o perfil distributivo deteriora-se, em um contexto de queda da renda média e de desestruturação do mercado de trabalho e de ampliação da insegurança do trabalhador. Nesse contexto, a parcela da renda do trabalho no conjunto da renda nacional apresenta uma queda vertiginosa e assustadora pelo pouco tempo em que essa situação se corporifica.

Nos anos 90 e no início do século XXI (dada a natureza do Plano Real e a forma de inserção da economia brasileira na chamada globalização econômica), a situação piora ainda mais, com a ampliação de uma outra forma de desigualdade, manifesta na ampliação dos gastos com juros em comparação com a ampliação dos gastos sociais. Essa nova face da desigualdade não é captada pelos indicadores tradicionais de distribuição de renda, mas tem papel decisivo para ampliar as desigualdades já existentes na sociedade brasileira. 


\section{NOTAS}

Versão anterior desse artigo foi apresentada no X Encontro Nacional de Economia Política, organizado pela Sociedade Brasileira de Economia Política (SEP), em Campinas (SP), em maio de 2005.

1. O conceito "heterogeneidade estrutural" será usado aqui como em Pinto (1979), que o utiliza para descrever as "descontinuidades" que caracterizaram o processo de desenvolvimento econômico na América Latina, diferentemente do que ocorreu nos países centrais, onde a expansão do capitalismo fez-se de forma mais homogênea, ou seja, sem grandes diferenças de produtividade intra e intersetoriais e sem grandes diferenças de renda e de posse da riqueza. Segundo Pinto (1979, p. 49), no processo de industrialização da América Latina houve uma "tríplice concentração dos 'frutos do progresso técnico', em nível social, dos 'estratos' econômicos e em nível regional".

\section{Ver, por exemplo, Carneiro (1989).}

3. Trabalhos como Dieese (2001), Pochmann (2001) e Dedecca (2003), por exemplo, apresentam a evolução da distribuição pessoal da renda e também dados e estimativas da distribuição funcional da renda.

4. A participação dos salários na renda nacional era de $40 \%$ em 1970, de 35\% em 1980 e de apenas 33\% em 1988, segundo dados publicados pelas Nações Unidas e citados por Carneiro (1989). De acordo com a publicação do ano de 1980 do "National Accounts Statistics of the United Nations", a participação dos salários na renda nacional era de $43 \%$ na Argentina, $45 \%$ na Venezuela, $42 \%$ no México, $39 \%$ na Coréia do Sul e de $40 \%$ no Paraguai (CARNEIRO, 1989).

5. Sobre problemas metodológicos relacionados à captação dos dados das PNADs, ver Sawyer (1989).

6. Conforme será demonstrado a seguir, com dados empíricos.

7. Pode-se afirmar que o processo de flexibilização do mercado de trabalho brasileiro deu seu primeiro passo no conjunto das reformas implementadas pelo Paeg, que substituiu o antigo estatuto da estabilidade no emprego pelo Fundo de Garantia por Tempo de Serviço - FGTS (e também pela repressão ao movimento sindical, pelo esvaziamento do Ministério do Trabalho, que, historicamente, tinha tido papel fundamental na construção do sistema corporativo das relações de trabalho no Brasil, com a instituição de reajustes automáticos de salários baseados em políticas salariais definidas pela equipe econômica dos diferentes mandatos do regime militar e também com a retirada do poder normativo da Justiça do Trabalho). Teve continuidade, de forma muito mais célere, nos últimos dez anos, pelo menos, com novas regulamentações de contratos temporários de trabalho, das leis que regem o uso e remuneração dos trabalhos de estagiários, etc., sempre com o objetivo (declarado ou não), por parte das autoridades econômicas, de baratear o uso da mão-de-obra por parte das empresas e também de diminuir o custo das demissões. Cf. Barbosa; Moretto (1998); e também artigos reunidos em Oliveira; Mattoso (1996), sobre a flexibilização do mercado de trabalho brasileiro. Em poucas palavras, esses autores consideram que existe flexibilidade no mercado de trabalho brasileiro, a qual se expressa de diversas formas: baixos salários e custos de demissão também baixos, pois são relacionados aos valores dos salários; frouxa regulamentação a respeito do uso de horas extras e de horários de exploração do trabalho (como, por exemplo, na relativamente recente lei que regulamenta a abertura do comércio aos domingos); sindicatos fracos e pouco representativos; esvaziamento crescente do papel do Ministério do Trabalho; ausência de convenções coletivas de trabalho; facilidades legais/ institucionais crescentes para demitir e contratar; elevada rotatividade da mão-de-obra; Justiça do Trabalho cada vez mais permeável ao discurso e práticas neoliberais de redução de custos como principal objetivo a ser cumprido pelas empresas; regulamen- tação pouco severa para com o uso de estagiários e aprendizes, o que retira possibilidades de emprego aos trabalhadores mais qualificados, entre outros fatores.

8. O salário mínimo, ainda segundo Souza (1980), serviria de fato como um "farol" a determinar os rendimentos assalariados e mesmo parcela expressiva dos rendimentos do trabalho autônomo dentro do espaço ocupacional brasileiro.

9. Trata-se, grosso modo, do que Kalecki chamou de "grau de monopólio", ou seja, as empresas dos setores oligopolizados desfrutam do poder de fixar preços nos mercados em que atuam. O que caracteriza a situação de oligopólio é justamente o fato de as empresas disporem de reserva de capacidade produtiva, a qual é muitas vezes construída estrategicamente de tal forma a responder rapidamente a flutuações positivas de demanda, evitando que eventuais concorrentes o façam. A demanda por produtos industriais, por seu lado, não surge "autonomamente" mas, pelo contrário, são açuladas pelas estratégias de vendas (publicidade, obsolescência acelerada de produtos, diferenciação de produtos e de modelos, aprimoramento das estratégias de distribuição, etc.) das empresas, de tal forma que elas podem também planejar as vendas e definir estratégias de determinação dos preços. O preço final do produto é calculado tendo como parâmetro mínimo o custo médio de produção, sobre o qual é acrescentada uma margem de lucro cuja magnitude depende do maior ou menor domínio que a empresa desfruta sobre o mercado em que atua - exatamente o que Kalecki define como "grau de monopólio". Sendo assim, quanto maior for o grau de monopólio, maior será a margem de lucro fixada pela empresa e, portanto, maior será o seu lucro. Fica claro que a magnitude da margem de lucro leva em conta também o preço de custo médio das demais empresas. No caso de uma estrutura industrial como a brasileira, que se constituiu sob o signo de uma forte heterogeneidade estrutural, com o convívio de setores modernos e avançados tecnologicamente ao lado e segmentos de baixa produtividade ligados a estruturas produtivas de empresas antigas e/ou atrasadas tecnologicamente, há diversos casos, em diferentes setores de atividades, de elevados "graus de monopólio", permitindo-se supor que os efeitos dessa configuração estrutural sejam sentidos no padrão de distribuição de renda mesmo dentro do setor capitalista, e também entre ele e os trabalhadores autônomos que vendem bens e serviços no mercado informal. Ademais, normalmente os salários dentro dos diversos setores industriais brasileiros são acentuadamente desiguais, refletindo as expressivas diferenças de produtividade e de "grau de monopólio" de certos conglomerados empresariais.

10. Conforme sublinhou Bacha (1975) "a relação entre a remuneração dos gerentes e os salários dos trabalhadores têm a ver não com sua importância funcional relativa, mas com a razão entre lucros e salários existentes na economia".

11. Sobre as relações entre a composição da riqueza nacional e a distribuição pessoal da renda do trabalho, ver Gonçalves (1999, p. 54): "A distribuição de renda não pode ser separada da questão da distribuição da riqueza. Proprietários de ativos reais e financeiros recebem rendas na forma de lucros, aluguéis e juros, além dos salários que remuneram o trabalho. A desigualdade na distribuição da riqueza é um tema de fundamental importância, principalmente em sociedades onde a distribuição funcional da renda tem um viés antisalarial. Este é, precisamente, o caso do Brasil, onde o salário representa uma parcela reduzida da renda comparativa a juros, lucros e aluguéis". Em outra passagem, debatendo os caminhos para uma melhoria na distribuição da renda no Brasil, o mesmo autor argumenta: "Os dados sugerem, na realidade, que o problema da distribuição da riqueza no Brasil precede ao problema da distribuição da renda. Neste sentido, o combate à pobreza no Brasil, que exige a combinação de crescimento com distribuição de renda, para ser eficaz e enfrentar definitivamente o problema, deveria ser complementado com políticas de redistribuição da riqueza".

12. O que aqui é denominado de "remuneração plena" representa o conjunto de itens que perfazem o conjunto da remuneração do tra- 
balho. Ou seja, além do salário mensal, também o décimo-terceiro salário, as férias pagas com adicional (no caso do adicional, depois da Constituinte de 1988), os depósitos de Fundo de Garantia e as licenças-maternidade ou paternidade remuneradas, e também as verbas rescisórias, quando for o caso (só para esclarecer a nomenclatura utilizada aqui: todos esses itens que vão além do salário mensal são chamados pelos economistas liberais, e/ou pela maior parte dos empresários, simplesmente de "encargos trabalhistas"; mas, do ponto de vista dos trabalhadores assalariados, são parte integrante de sua remuneração anual pelo trabalho realizado). Sobre uma discussão não-afeita aos preceitos do pensamento conservador a respeito dos encargos sociais e do custo do trabalho no Brasil, ver Santos (1996).

13. Quando até mesmo o valor da remuneração mensal é incerto e excessivamente sujeito às oscilações do ciclo econômico (e até mesmo à sua saúde) a cada mês.

14. Ao afirmar isso, não está-se perdendo de vista que persistiam, no mercado de trabalho brasileiro, sinais inequívocos do subdesenvolvimento, como baixos salários, desigualdades de todos os tipos (de renda do trabalho, de renda funcional, de renda por regiões), informalidade, emprego precário em grande quantidade, etc., conforme mencionado em outros tópicos desse artigo. Mas a situação do trabalho, no geral, melhorou bastante ao longo do auge do processo de industrialização brasileira. Essa situação começou novamente a se deteriorar a partir da crise dos anos 80, quando surge um outro problema: o desemprego (DEDECCA, 1990; 2005).

15. Ver Belluzzo; Coutinho (1982; 1983). Com relação aos efeitos, sobre a economia brasileira dos anos 80 , do endividamento externo constituído nos anos 70, ver especialmente, Cruz (1983). Obra mais recente - e igualmente importante - que trata dessas questões é a de Carneiro (2002).

16. Para uma análise detalhada do aumento da informalidade no mercado de trabalho brasileiro nos anos 80 e de seu impacto sobre os perfis distributivos, ver Mattos (1994).

17. Vale registrar a seguinte passagem de Malan e Wells (1975), notórios opositores da doutrina liberal/conservadora que norteou a interpretação do regime militar a respeito do aumento das desigualdades de renda ao longo dos anos 60: "[...] entretanto, acreditar na expansão apropriada da oferta como 'solução' para o longo prazo é seriamente discutível, e por várias razões, mas queríamos mencionar uma aqui em particular, derivada dos resultados empíricos do próprio Langoni. Com efeito, do aumento da variância total da renda entre 1960 e 1970 'explicado' pela variável educação, 35\% são devidos simplesmente a mudanças na composição educacional da força de trabalho, $23 \%$ a mudanças nas rendas relativas entre diferentes níveis de educação e $42 \%$ á crescente desigualdade na distribuição para um nível de escolaridade, isto é, educação é uma importante variável explicativa principalmente devido à crescente diferenciação de renda entre indivíduos com o mesmo nível educacional. E é precisamente sobre esse fenômeno que o mecanismo de oferta e procura é incapaz de dizer qualquer coisa, e que, não obstante o otimismo de Langoni, pode persistir e intensificar-se ao longo do tempo".

18. Para uma revisão detalhada a respeito dos argumentos presentes no debate sobre a concentração da renda nacional nos anos 60 , ver Mattos (1993).

19. Remuneração dos empregados é a soma dos salários às contribuições sociais efetivas.

20. Para maiores detalhes sobre a natureza dessa inserção, ver Filgueiras (2000, cap. 1).

21. Ver Mattos (1994). O autor mostra que o nível e a dispersão dos rendimentos dos autônomos no setor informal estão relacionados aos diferentes graus de desenvolvimento econômico atingido por diferentes metrópoles, que conformarão não só um setor formal e dinâmico, mas também um setor informal (ligado e deri- vado do formal) com distintos conteúdos ocupacionais, e, portanto, com distintos perfis de distribuição da renda do trabalho.

22. Vale citar uma passagem de Coutinho (1984, p. 39): “A distribuição pessoal (da renda) é apenas um resultado de fenômenos dispersos que ocorrem de modo diverso em cada sociedade humana. Alguns destes fenômenos têm natureza econômica; outros decorrem de aspectos institucionais ou extra-econômicos, embora contribuam para a explicação de um atributo econômico: a renda".

\section{REFERÊNCIAS BIBLIOGRÁFICAS}

BACHA, E. Hierarquia e remuneração gerencial. In: TOLIPAN, R.; TINELLI, A.C. (Org.). A controvérsia sobre distribuição de renda e desenvolvimento. Rio de Janeiro: Zahar, 1975.

BALTAR, P.E.A. Crise contemporânea e mercado de trabalho no Brasil. In: OLIVEIRA, M.A. (Org.). Economia e Trabalho textos básicos. Campinas: Instituto de Economia/Unicamp, 1998 .

BALTAR, P.E.A.; DEDECCA, C.; HENRIQUE, W. Mercado de trabalho e exclusão social no Brasil. In: OLIVEIRA, C.A.B.; MATtOSO, J. (Org.). Crise e trabalho no Brasil: modernidade ou volta ao passado? São Paulo: Scritta, 1996.

BARbosA, A.; MORETTO, A. Políticas de emprego e proteção social. Associação Brasileira de Estudos do Trabalho, v. 1, 1998. (Coleção Abet).

BElluzZO, L.G.M.; COUTINHO, R. (Org.). Desenvolvimento capitalista no Brasil - ensaios sobre a crise. São Paulo: Brasiliense, 1983. v. 2.

. Desenvolvimento capitalista no Brasil - ensaios sobre a crise. São Paulo: Brasiliense, 1982. v. 1.

CARDOSO DE MELLO, J.M. Capitalismo tardio. São Paulo: Brasiliense, 1982.

CARNEIRO, F.G. Some estimates on wages and profit relative shares in Brazil. In: World Bank, July, 1989.

CARNEIRO, R. Desenvolvimento em crise: a economia brasileira no último quarto do século XX. São Paulo: Ed. Unesp, Instituto de Economia/Unicamp, 2002.

CASTRO, A.B.; LESSA, C. Introdução à economia: uma abordagem estruturalista. 33. ed. Rio de Janeiro: Forense Universitária, 1991.

COUTINHO, M. Distribuição de renda e mobilidade social no Brasil. Tese (Doutorado) - Instituto de Filosofia e Ciências Humanas/Unicamp, Campinas, 1984.

CRUZ, P.R.D. Notas sobre o endividamento brasileiro nos anos setenta. In: BELLUZZO, L.G.M.; COUTINHO, R. (Org.). Desenvolvimento capitalista no Brasil - ensaios sobre a crise. São Paulo: Brasiliense, 1983. v. 2.

DEDECCA, C.S. Notas sobre a evolução no mercado de trabalho no Brasil. Revista de Economia Política, São Paulo, Ed. 34, v. 25, n. 1 (97), jan./mar. 2005.

Anos 90: a estabilidade com desigualdade. In: PRONI, M.; HENRIQUE, W. (Org.). Trabalho, mercado e sociedade: o Brasil nos anos 90. São Paulo: Ed. Unesp; Campinas: Ed. da Unicamp, 2003. 
Dinâmica econômica e mercado de trabalho urbano: uma abordagem da Região Metropolitana de São Paulo. Tese (Doutorado) - Istituto de Economia/Unicamp, Campinas, 1990

DIEESE. A situação do trabalho no Brasil. São Paulo: Dieese, 2001

EDWARDS, R.; REICH, M.; GORDON, D. (Org.). Labor market segmentation. Massachussetts, D.C.: Health Company, 1975.

FILGUEIRAS, L. História do Plano Real. São Paulo: Boitempo Editorial, 2000.

GONÇALVES, R. Distribuição de riqueza e renda: alternativa para a crise brasileira. In: LESBAUPIN, I. (Org.). O Desmonte da Nação - balanço do governo FHC. Petrópolis, RJ: Vozes, 1999

KALECKI, M. Teoria da dinâmica econômica: ensaio sobre as mudanças cíclicas e a longo prazo da economia capitalista. São Paulo: Abril Cultural, 1983.

LANGONI, C.G. Distribuição de renda e crescimento econômico no Brasil. Rio de Janeiro: Expressão e Cultura, 1973.

LESBAUPIN, I. (Org.). O Desmonte da Nação - balanço do governo FHC. Petrópolis, RJ: Vozes, 1999.

MALAN, P.; WELLS, J. Distribuição de renda e desenvolvimento econômico no Brasil. In: TOLIPAN, R.; TINELLI, A.C. (Org.). A controvérsia sobre distribuição de renda e desenvolvimento. Rio de Janeiro: Zahar, 1975.

MATTOS, F.A.M. Emprego e distribuição de renda nas Regiões Metropolitanas de São Paulo e do Rio de Janeiro: os anos 80. Dissertação (Mestrado) - Instituto de Economia/Unicamp, Campinas, 1994.

Desenvolvimento econômico e distribuição de renda no pós-guerra na América Latina. Revista Horizontes (USF). Bragança Paulista, Ed. USF, v. 11, n. 2, jul./dez. 1993.

MATTOS, F.A.M.; CARDOSO Jr., J.C. Novas evidências acerca da questão distributiva pós-Plano Real. Leituras de Economia Política, Campinas, Instituto de Economia da Unicamp, n. 7, p. 29-55, jun./dez. 1999.

OLIVEIRA, C.A.B.; MATTOSO, J. (Org.). Crise e trabalho no Brasil: modernidade ou volta ao passado? São Paulo: Scritta, 1996

OLIVEIRA, C.A.B. Formação do mercado de trabalho no Brasil. In: OLIVEIRA, M.A. (Org.). Economia e Trabalho - textos básicos. Campinas: Instituto de Economia/Unicamp, 1998.

OLIVEIRA, M.A. (Org.). Economia e Trabalho - textos básicos. Campinas: Instituto de Economia/Unicamp, 1998.
PINTO, A. Heterogeneidade estrutural e modelo de desenvolvimento recente. In: SERRA, J. (Org.). América Latina - ensaios de interpretação econômica. 2. ed. Rio de Janeiro: Paz e Terra, 1979.

POCHMAnN, M. A década dos mitos. São Paulo: Contexto, 2001.

O trabalho sob fogo cruzado. São Paulo: Contexto,

PRONI, M.; HENRIQUE, W. (Org.). Trabalho, mercado e sociedade: o Brasil nos anos 90. São Paulo: Ed. Unesp; Campinas: Ed. da Unicamp, 2003.

SANTOS, A.L. Encargos sociais e custo do trabalho no Brasil. In: OLIVEIRA, C.A.B.; MATTOSO, J. (Org.). Crise e trabalho no Brasil: modernidade ou volta ao passado? São Paulo: Scritta, 1996.

SAWYER, D.O. (Org.). PNAD's em Foco - anos 80. Abep, 1989.

SERRA, J. (Org.). América Latina - ensaios de interpretação econômica. 2. ed. Rio de Janeiro: Paz e Terra, 1979.

SINGER, P. Curso de Introdução à Economia Política. 13. ed. Rio de Janeiro: Forense Universitária, 1991.

SINGER, P. Desenvolvimento e repartição da renda. In: TOLIPAN, R. e TINELLI, A.C. (Org.). A controvérsia sobre distribuição de renda e desenvolvimento. Rio de Janeiro: Zahar, 1975 .

SOUZA, P.R. Emprego, salários e pobreza. São Paulo: Hucitec, 1980 .

TOLIPAN, R.; TINELLI, A.C. (Org.). A controvérsia sobre distribuição de renda e desenvolvimento. Rio de Janeiro: Zahar, 1975.

Fernando Augusto Mansor de Mattos: Doutor em Economia pelo Instituto de Economia da Unicamp. Professor e Pesquisador do Centro de Economia e Administração da PUC-Campinas e do Programa de Pós-Graduação em Ciência da Informação da PUC-Campinas.

Artigo recebido em 5 de abril de 2005.

Artigo aprovado em 12 de junho de 2005. 